\title{
NASA budget falls foul of contracts
}

\section{Washington}

The National Aeronautics and Space Administration (NASA) has been caught in crossfire between the US Congress and the Office of Management and Budget (OMB) over whether the federal bureaucracy is spending too much money in employing private consultants to carry out its work. This has resulted in a demand from the Senate that NASA cut $\$ 14$ million from a budget for consultant services which NASA claims totals only $\$ 4.3$ million, but which the Senate Appropriations Committee, using a broader definition disputed by both the agency and the OMB, claims to be more than $\$ 90$ million.

Unless it is reversed during negotiations with the House, the extra cut in NASA's budget, coming on top of a proposed two per cent reduction (approximately $\$ 100$ million) in its budget request, will mean further pressure on space research projects as efforts are made to protect the space shuttle programme.

The pressures are already beginning to bite. For example, NASA is planning a reduction in the scope of experiments to be carried out by the spacecraft which will take part in the international solar polar mission, due for launch in 1982. Scientists from the European Space Agency, which is providing the second spacecraft in a dual mission, argue that the omission of instrumentation from the US craft could reduce the value of their own findings.

The proposed cuts in NASA's consultancy contracts reflect a general unease in Congress about the way in which federal agencies have come to rely increasingly on outside contractors to meet their responsibilities.

However, the agencies face a dilemma. On the one hand, Congress is continually increasing their work-load while, on the other, the Administration is keen to keep down the cost and size of government. The inevitable result is that the agencies contract work out. This, in turn, provides ample scope for disputes over rigged bidding for contracts, favouritism towards contractors, duplication of work and conflicts of interest.

Several instances of such practices have come to light in the past year. Last week, for example, officials from the Department of Energy admitted before a congressional oversight hearing that they had failed to check up on a consultancy firm employed to help draw up clean air regulations and were therefore unaware that the firm had also been working for companies engaged in a campaign to oppose the Clean Air Act of 1977.

In debating the 1981 budgets for a number of independent federal agencies, the Senate agreed to a proposal from Senator Warren Magnusson, chairman of the Appropriations Committee, to make a
15 per cent cut in the consultancy budgets of three agencies - NASA, the Environmental Protection Agency and the Department of Housing and Urban Development.

In opposing the proposed cuts, NASA complained that the analysis on which they had been calculated did not reflect the difference between narrowly defined contracts for advisory services and service contracts essential to a range of space programmes, including the shuttle.

Strong support for NASA's activities came from Senator Adlai Stevenson and ex-astronaut Senator Jack Schmitt, chairman and ranking minority member of the Senate Science and Space Subcommittee. Mr Schmitt proposed as an alternative that the 15 per cent reduction be according to NASA's own definition of what constitutes a consultant - this would reduce its budget by only $\$ 640,000$.

However, Mr Magnusson and fellow Appropriations Committee member Senator William Proxmire remained firm. $\mathrm{Mr}$ Magnusson quoted a recent report from the General Accounting Office citing OMB's apparent failure significantly to reduce excessive waste, and its abuse of consultants' contracts over a 20-year period, as well as a statement from Admiral Hyman Rickover that "the use of consultants often impedes, rather than facilitates, action by government agencies'. Mr Schmitt's amendment was

\section{Einstein Observatory in trouble}

\section{Washington}

Equipment problems on board the National Aeronautics and Space Administration (NASA)'s second HighEnergy Astronomical Observatory (HEAO 2) - also known as the Einstein Observatory - are causing concern that the mission may have to be brought to a premature end.

Initially the satellite, which was launched in 1978 and has provided the first $\mathrm{X}$-ray telescope as sensitive as groundbased optical telescopes, was planned to operate only for one year. But after its initial success in generating new scientific data, the mission was extended, and until the recent setback NASA scientists hope the satellite would continue to send back data well into next year, when atmospheric drag would take it out of orbit.

How long the satellite goes on operating, however, will now depend on the behaviour of the gyroscopes used to position it. Three weeks ago, the transmission of scientific data had to be temporarily shut down after the failure of two of the six gyroscopes to switch on after a temporary black-out.

The satellite needs three functioning gyroscopes to position itself. One is already lost by 27 votes to 66 .

NASA is not the only agency in trouble about consultants. The Environmental Protection Agency (EPA) announced last Friday the cancellation of a $\$ 285,000$ contract of fered to a research worker at the California Institute of Technology to study the health effects of radon gas because of charges that the contract had improperly been awarded to the university without competitive bidding.

Dr David M. Rosenbaum, head of EPA's Office of Radiation Programs, had offered the contract to the university without seeking other bids on the basis that Caltech was the only contractor qualified to carry out the work involved. However, a university research worker told a Senate committee last Thursday that there were other contractors who could have carried out the same work.

Dr Rosenbaum also justified his actions on the grounds that it would have taken nine months to secure the services of a consultant through competitive bidding, and that because radon was a "serious health problem", fast action was needed.

However, his superior at EPA said that Dr Rosenbaum may have violated the agency's procurement regulations in making the award. And the agency's inspector general said that she had found "serious and troublesome" problems in the contracts procedures used by the radiation office.

David Dickson

dead, and another has been working erratically for some time. The latter, however, has now had to be brought back into service in the hope that its performance will be adequate. If not, NASA officials said last week that they are developing software instructions for a back-up control system which would use the two gyroscopes that are still functioning, as well as either a sun sensor or a star tracker on the satellite.

At Harvard University, whose Center for Astrophysics is responsible for collecting the data transmitted from the Einstein Observatory, scientists also fear that even if the observatory continues to operate satisfactorily - as they are now hoping - the extra fuel consumed during recent manoeuvring to keep solar power cells facing the sun will shorten its lifetime by a couple of months.

The trouble on HEAO 2 started when one of the thrusters on the satellite started to burn for longer than it should during a repositioning manoeuvre. The gyroscopes were subsequently turned off with other equipment, but two failed to start when power was switched back on.

The gyroscopes have given trouble once before at the start of the mission in 1978, 
but this was resolved by NASA engineers. Ironically, while the problems with HEAO 2 were being worked on, gyroscope problems also developed in its successor HEAO 3, which was intended merely for a six-month mission.

In this case, a command sent to $\mathrm{HEAO} 3$ caused it inadvertently to start drifting from its proper position, leading its control computers to switch the satellite into a "safe" mode. However, this problem is again said by NASA engineers to have been solved.

The HEAO satellites are not the only space activities encountering technical problems. Thus NASA officials are now carrying out an in-depth review of the space telescope programme and are concerned about the possible combined effects of cost overruns and schedule slips.

The critical design review of the telescope has been put back from this summer until January 1981, partly because of the need to redesign the wide-field planetary camera to save weight. In addition, the fine-polishing of the primary mirrors for the telescope is behind schedule; and various contractors for the space telescope project, due to be launched from the space shuttle in early 1984, are complaining that they have been allocated insufficient manpower and funds to keep the programme on schedule.

NASA is soon expected to announce the results of a competition for the location of the Space Telescope Institute, which will collect and analyse data from the telescope. The three main contenders are Johns Hopkins University in Baltimore, Princeton University and the Fermi National Accelerator near Chicago. Two groups - Associated Universities Inc. and Universities Space Research Association have drawn up separate plans for locating the institute at Princeton. The Baltimore site is being proposed by the Association of Universities for Research in Astronomy and Fermilab by the Universities Research Association Inc., which already operates the laboratory's accelerator for the Department of Energy.

\section{David Dickson}

\section{Radiation safety}

\section{X-ray survey}

A plea for more effective steps to reduce the radiological dose to the gonads of patients from X-ray diagnosis has been put out by the National Radiological Protection Board (NRPB). The board is especially concerned about young adults, and says that if they were protected as well as children usually are, then the genetically significant dose to the British population from diagnostic radiology could be reduced by $40-50$ per cent.

The NRPB set out to investigate whether the lessons from a similar study in 1957 under Lord Adrian had been learnt. That study concluded that the dose to the gonads of individuals could be reduced by the use of better radiological techniques, such as narrower beam widths. It also found that gonad dose from the same types of examination varied considerably, sometimes by as much as a factor of three or four between different parts of the United Kingdom.

The new study has found that the genetically significant dose - the average gonad dose per head of population weighted for child expectancy data - has remained approximately the same over the past 20 years despite a 50 per cent increase in the annual number of radiological examinations, suggesting that techniques have indeed improved. But it has also found that local variations in dose for the same examinations are as great as they were in 1957, suggesting that the use of gonad protection varies from place to place.

With this said, the NRPB is not alarmed. The "genetically significant dose" in Britain is still considerably less than in most other industrialized countries and could be responsible for a total of 100 genetic defects a year compared with a rate of 20,000 cases of genetic birth damage each year. Nevertheless, according to one of the reports, a reduction of only 10 per cent in the contribution to the genetically significant dose from diagnostic radiology would be the equivalent of the present contribution from nuclear power. As techniques for reducing the radiological contribution are easily available and relatively inexpensive compared with those needed to achieve a similar reduction from nuclear power, the NRPB says they should be implemented.

The study, based on data about radiological investigations in 1977, measured the gonadal dose in a sample of patients undergoing different types of examinations. The genetically significant dose is inferred from child expectancy data.

A breakdown of examinations into type reveals that most have increased in frequency whereas a few have decreased. A substantial factor in keeping the genetically significant dose down to its 1957 level is the large reduction in the number of obstetric radiological examinations. Their contribution to the genetically significant dose has fallen from $4.5 \mathrm{mrad}$ in 1957 to 0.6 mrad now.

Although the NRPB study claims that there is probably room for further reductions of the genetically significant dose, it has few practical suggestions as to how this might be done. Nor does the NRPB fully understand the large differences of gonadal doses for the same examination in different parts of the country. It also acknowledges that gonad shields cannot be used in all cases, especially where they would obscure organs to be investigated. The plan is to discuss the findings with radiologists later in the year in the hope of finding ways to reduce the genetically significant dose.

Judy Redfearn

\section{DNA guidelines}

\section{More relaxation}

\section{Washington}

The National Institutes of Health (NIH) are expected shortly to reduce the burden of recombinant DNA regulations on research workers. This follows the recommendation of the institute's Recombinant DNA Advisory Committee (RAC) that details of virtually all experiments covered by the current safety guidelines need no longer be submitted to NIH for review.

At the same time, RAC has decided that NIH should limit their attempts to oversee recombinant DNA activities carried out in the private sector. In particular, the committee has proposed a procedure for checking on the biological aspects of largescale experiments, but is suggesting that it should now restrict itself to general comments on the physical aspects of the fermentation and containment technology rather than reviewing each proposal submitted.

RAC has not gone as far as some would like. At a meeting in Bethesda, Maryland, last week, it decided to defer action on a proposal that clearance from local institutional biosafety committees (IBCs) should no longer be required before a research worker carries out an experiment in containment conditions specified in the guidelines.

The proposals for a procedural change in the guidelines were put to RAC by $\mathrm{Dr}$ Maxine Singer, head of the National Cancer Institute's biochemistry laboratory and a prominent participant in the 1973 Gordon conference which first drew attention to the need for caution in recombinant DNA research.

Dr Singer told the committee that many scientists felt that there was unnecessary delay in waiting for the Memoranda of Understanding and Agreement, required by NIH, to be approved by IBCs before research was allowed to begin. Also, there was impatience with the requirement for central review of experiments where the safety procedures to be followed were relatively straightforward.

On the latter point, committee members readily accepted Dr Singer's proposal that central registration be eliminated. Such registration is already no longer required for the bulk of recombinant DNA experiments, those carried out with the disabled K12 strain of the bacterium Escherichia coli. The new proposal would chiefly affect experiments being conducted in $\mathrm{P} 2$ and $\mathrm{P} 3$ physical containment conditions; the status of experiments now requiring the NIH director's explicit approval would not be altered.

More controversial was the proposal to remove the requirement for prior review of experiments by IBCs. Debate on this was coloured by a report presented to the committee on the performance of 19 IBCs 